these, in tracts as long as the Appalachians, are essential preliminaries to the understanding of the relations of structures on either side of the Atlantic and ultimately to a comprehension of the global tectonics of the past.

Few geological problems have been investigated for 400 years by scientists from so many countries, for nowhere else in the world has the population on one side of an ocean opened by continental drift migrated in such numbers to the opposing shore. It is a fitting tribute to this long collaboration that Rodgers, an American, should dedicate the book to the memory of Fallot and that it appears in a series edited by another great European structural geologist, de Sitter. Probably neither de Soto nor Maclure ever dreamed that the New World they had entered was once linked to the one they had left.

\section{J. SUTTON}

\section{Busy as Bees}

Insect Pollination of Crops. By John B. Free. Pp. xi +544 . (Academic: London and New York, December 1970.) $£ 7.25$.

IT is salutary to be reminded that mankind is dependent on the success of pollination for all plant products which are used for food or as processed com- modities, which is why it seems rather strange that this should be the first comprehensive review of the subject. But, as Dr Free so clearly demonstrates, mechanical transfer of pollen from anther to stigma is only one facet of a complex and fascinating process which, if successful, leads to fertilization of the ovule. Full understanding of these mechanisms requires a study of the behavioural characteristics of insects which must be closely integrated with morphological features and physiological processes of the plant.

This book is a detailed review of the literature, in which botanical aspects receive as much attention as the insects. The first part, although entitled "Insect Pollinators", deals exclusively with species that can be manipulated to a greater or lesser extent by man-honey bees, bumble bees and a few species of wild bees. All the salient information on behaviour, management and utilization is presented clearly and concisely. To satisfy the curiosity of a reader who wishes to know which species other than Hymenoptera are associated with pollination; to discover, for instance, that midges pollinate para rubber, or that humming birds are thought to pollinate pineapple, or even to be disillusioned about the importance of pollen beetles (which, incidentally, do not even get into the index) in relation to Brassicas,

\title{
Nineteenth Century Steam Engine
}

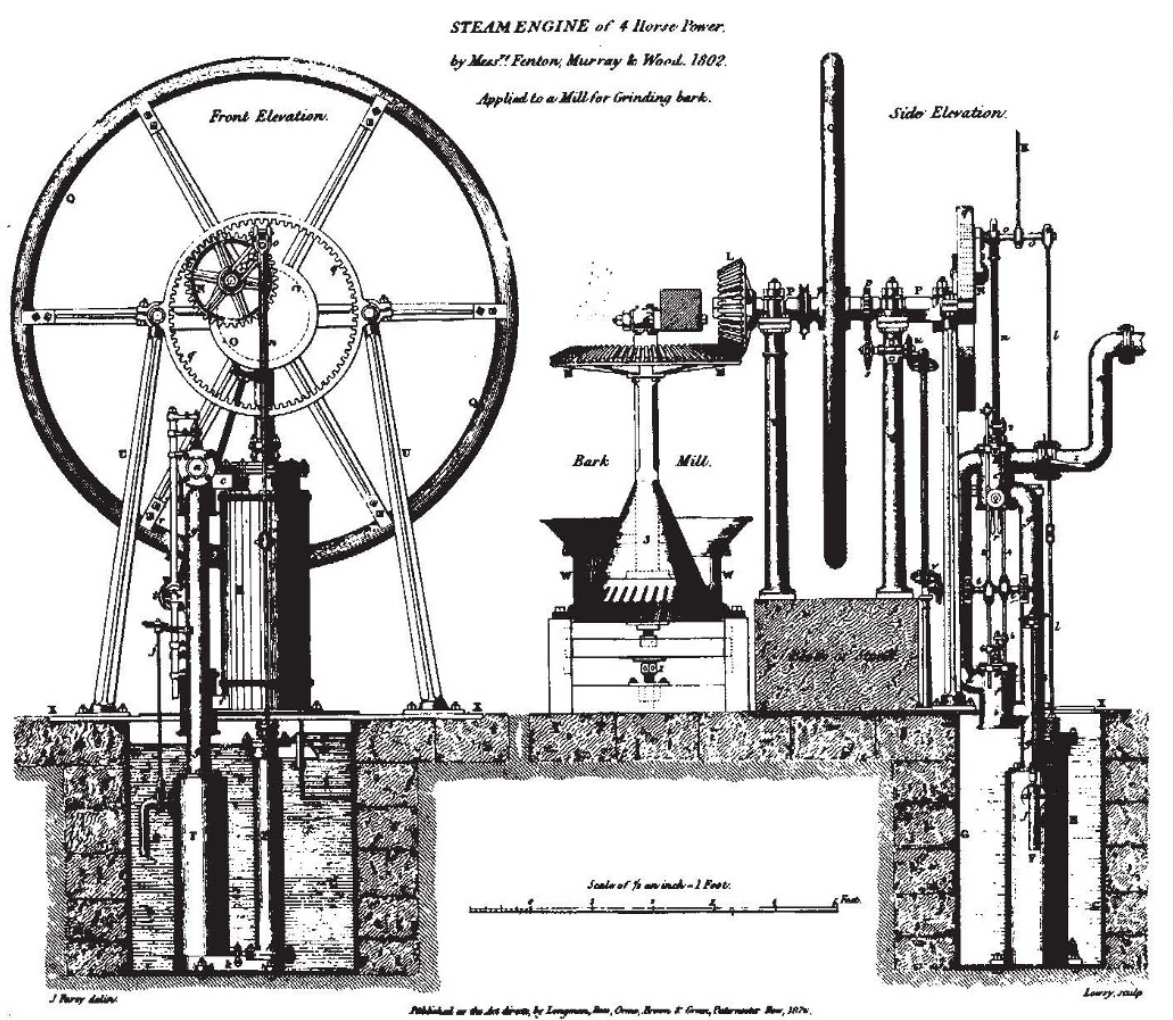

Plate XVII from John Farey's A Treatise on the Steam Engine (1827) now reprinted by David and Charles, $£ 8.40$.

it is necessary to consult the animal index. It then becomes clear that these receive detailed comment in later chapters dealing with their respective host plants. Even at the expense of some duplication, I would have preferred a comprehensive list of all species in the first section.

The remaining two-thirds of the book consist of a chapter on each plant family which produces edible or other useful products, but excludes ornamentals, timber and those plants in which wind plays the dominant role in dispersal of pollen. Here, botanical features receive the same detailed attention as was given earlier to the social Hymenoptera. The morphology of the flower is illustrated, the period when anthers dehisce, when the stigma is receptive, germ tube growth, and composition of the nectar are all described in detail, together with insects associated with pollination and results of experiments on insect pollination. A recurrent feature of experimental work, which has been largely concerned with honey bees, is the lack of consistency between results obtained by different workers, doubtless because of the empirical approach or the insufficiency of data, with the result that the author has been unable to draw more than tentative conclusions about the benefits obtained. However, with intensification of agriculture, the trend towards monoculture and increasing demands for higher yields and greater uniformity of produce, it is clear that, with many crops, optimal yields will be obtained only if wild pollinators are supplemented by species that can be easily manipulated.

To avoid the shortcomings of much earlier experimental work this book, a distillation of current knowledge, should be compulsory reading for all future workers, whether in cool, temperate or tropical regions. It is essentially a reference book, meticulously crossreferenced, with a huge bibliography and a good index.

\section{G. H. L. DICKeR}

\section{Burning Issues}

The Chemistry and Uses of Fire Retardants. By John W. Lyons. (WileyInterscience: London and New York, January 1970.) $£ 5.75$.

THE ease with which thin sections of wood and fibrous cellulosic materials and textiles catch fire has been known for centuries, and treatments have been sought to reduce this risk. The use of flammable synthetic polymers as substitutes for, and in addition to, cellulosic materials has been increasing rapidly during the second half of this century, and the search for and use of flame retardant treatments has been extended 